ARTICLE

https://doi.org/10.1038/s41467-019-12887-y

\title{
Atomic layer deposited Pt-Ru dual-metal dimers and identifying their active sites for hydrogen evolution reaction
}

Lei Zhang ${ }^{1,8}$, Rutong $\mathrm{Si}^{2,3,8}$, Hanshuo Liu ${ }^{4,8}$, Ning Chen ${ }^{5}$, Qi Wang ${ }^{6}$, Keegan Adair ${ }^{1}$, Zhiqiang Wang (1) ${ }^{7}$, Jiatang Chen (1) 7, Zhongxin Song ${ }^{1}$, Junjie Li', Mohammad Norouzi Banis (1) ${ }^{1}$, Ruying Li ${ }^{1}$, Tsun-Kong Sham , Meng Gu${ }^{6}$, Li-Min Liu (1) ${ }^{3 \star}$, Gianluigi A. Botton (i) ${ }^{4 \star} \&$ Xueliang Sun ${ }^{1 \star}$

Single atom catalysts exhibit particularly high catalytic activities in contrast to regular nanomaterial-based catalysts. Until recently, research has been mostly focused on single atom catalysts, and it remains a great challenge to synthesize bimetallic dimer structures. Herein, we successfully prepare high-quality one-to-one A-B bimetallic dimer structures (PtRu dimers) through an atomic layer deposition (ALD) process. The Pt-Ru dimers show much higher hydrogen evolution activity (more than 50 times) and excellent stability compared to commercial Pt/C catalysts. X-ray absorption spectroscopy indicates that the Pt-Ru dimers structure model contains one Pt-Ru bonding configuration. First principle calculations reveal that the Pt-Ru dimer generates a synergy effect by modulating the electronic structure, which results in the enhanced hydrogen evolution activity. This work paves the way for the rational design of bimetallic dimers with good activity and stability, which have a great potential to be applied in various catalytic reactions.

\footnotetext{
${ }^{1}$ Department of Mechanical and Materials Engineering, The University of Western Ontario, London, ON N6A 5B9, Canada. ${ }^{2}$ Beijing Computational Science Research Center, Beijing 100193, China. ${ }^{3}$ School of Physics, Beihang University, Beijing 100083, China. ${ }^{4}$ Department of Materials Science and Engineering, McMaster University, Hamilton, ON L8S 4L8, Canada. ${ }^{5}$ Canadian Light Source Inc, Saskatoon, SK S7N 2V3, Canada. ${ }^{6}$ Department of Materials Science and Engineering, Southern University of Science and Technology, Shenzhen 518055, China. ${ }^{7}$ Department of Chemistry, University of Western Ontario, London, ON N6A 5B7, Canada. ${ }^{8}$ These authors contributed equally: Lei Zhang, Rutong Si, Hanshuo Liu. *email: liminliu@buaa.edu.cn; gbotton@mcmaster.ca; xsun@eng.uwo.ca
} 
S ingle atom catalysts (SACs), a new frontier in catalysis with the highest atom utilization and abundant active sites, have shown particularly high catalytic activities compared to regular metal nanoparticles $(\mathrm{NPs})^{1-4}$. By decreasing catalyst size to the single atom level, the atom utilization efficiency would be maximized ${ }^{5-8}$. Simultaneously, the electronic structure of catalysts is tuned by their coordination number, quantum size effects and the interaction with the support. Thus, SACs usually exhibit distinct catalytic properties as compared to metal NPs. Many methods have been developed for preparing different types of SACs, such as co-precipitation methods ${ }^{9-12}$, wet impregnation methods ${ }^{13-16}$, atomic layer deposition (ALD) methods ${ }^{17-21}$, spatial confinement strategies $22,23-28$, and photochemical reduction methods ${ }^{29-31}$, etc. Recently, dual-metal sites, such as Fe-Co and $\mathrm{Co}-\mathrm{Zn}$, were found exhibit greatly enhanced activities, which was attributable to the synergistic effects between the electronic structures of the two elements ${ }^{32,33}$. However, the dual-metal sites were all synthesized by pyrolyzing two metal precursors simultaneously, which can not precisely control the location of each metal site. Therefore, it remains a great challenge to synthesize high-quality one-to-one A-B bimetallic dimer structures.

Among different methods for the preparation of SACs, ALD method can provide a precise control of the catalysts from the single atoms to nanoclusters, which makes it a powerful tool for investigating the relationship between the SAC structure and their catalytic performance. In 2013, our group firstly reported the synthesis of atomic layer deposited $\mathrm{Pt}$ single atoms on graphene nanosheets ${ }^{17}$. The as-prepared $\mathrm{Pt}$ single atoms exhibit greatly enhanced electrochemical activities in contrast to commercial Pt/ $\mathrm{C}$ catalysts. Besides, the ALD technique provides the possibility to achieve atomically precise ultrafine metal clusters, even bimetallic sites. It should be pointed out that the ALD prepared dimer structures might be distinct from the reported dual-metal-sites. Through careful control of the deposition conditions, the second metal (e.g., $\mathrm{Ru}$ ) can only attach on the preliminary one (e.g., $\mathrm{Pt}$ ), selectively forming the bimetallic dimer structure.

$\mathrm{Pt}-\mathrm{Ru}$ bimetallic catalysts have been proven to be an effective catalyst for several electrochemical catalytic reactions ${ }^{34,35}$. It can be expected that the electronic structure of $\mathrm{Pt}-\mathrm{Ru}$ will be significantly tuned with the formation of bimetallic Pt-Ru dimer structure. Herein, we report an ALD route to prepare $\mathrm{Pt}-\mathrm{Ru}$ dimers on nitrogen-doped carbon nanotubes (NCNT). The asprepared $\mathrm{Pt}-\mathrm{Ru}$ dimers show much higher mass activity and significantly improved stability compared with commercial $\mathrm{Pt} / \mathrm{C}$ catalysts for hydrogen evolution reaction (HER). The detailed structure of the $\mathrm{Pt}-\mathrm{Ru}$ dimers has been investigated by scanning transmission electron microscopy (STEM), X-ray absorption near edge structure (XANES), and extended X-ray absorption fine spectra (EXAFS). Density functional theory (DFT) calculation results indicate that the $\mathrm{Pt}$ atom strongly affects the electronic structure of the $\mathrm{Ru}$ atom, where the bimetallic dimer proceeds metallicity to covalence transformation, which results in the high HER performance.

\section{Results}

ALD preparation and characterization of Pt-Ru dimers. As shown in Fig. 1, we prepared the Pt-Ru dimers on NCNTs via a two-step ALD process. Firstly, the isolated $\mathrm{Pt}$ atoms were obtained by using trimethyl(methylcyclopentadienyl)-platinum (IV) $\left(\mathrm{MeCpPtMe}_{3}\right)$ as the precursor, and nitrogen $(99.9995 \%)$ as purge gas. During the ALD process, the Pt precursor tends to absorption and react with the $\mathrm{N}$ atoms on NCNTs, forming the strong metal-support interaction via the chemical bonding between $\mathrm{Pt}$ SAs and $\mathrm{N}$-doping sites. The Pt single atoms were characterized by aberration-corrected high angle annular dark field scanning transmission electron microscopy (HAADFSTEM) imaging. The contrast in HAADF-STEM images is highly dependent on the atomic number $(\mathrm{Z})$ of the elements in the material and linearly related the thickness of the sample. Therefore, compared to the carbon support, the heavier $\mathrm{Pt}$ atoms exhibited brighter intensity in the HAADF-STEM images. As shown in Supplementary Fig. 1 that many isolated $\mathrm{Pt}$ atoms (sharp bright spots) are uniformly dispersed on the NCNTs. The Pt loading amount was confirmed to be $0.9 \mathrm{wt} \%$ by inductively coupled plasma-optical emission spectrometer (ICP-OES). As the ALD temperature for $\mathrm{Ru}$ deposition is $270^{\circ} \mathrm{C}$, which is higher than that for Pt ALD, we maintained the Pt single atoms in ALD chamber at $270^{\circ} \mathrm{C}$ for $1 \mathrm{~h}$ to investigate the stability of the $\mathrm{Pt}$ single atoms. As shown in Supplementary Fig. 2, the Pt single atoms maintained their structure at the $\mathrm{Ru}$ ALD deposition conditions.

Then the Pt-Ru dimers were achieved by ALD of $\mathrm{Ru}$ on $\mathrm{Pt}$ single atoms using bis(ethylcyclopentadienyl)ruthenium(II) as precursors. Recently, we reported that $\mathrm{Ru}$ atoms can not be deposited on NCNTs in the first several ALD cycles ${ }^{36}$. This result indicates that Ru atoms are not effectively attached onto NCNTs during the several initial ALD cycles, which provided the necessary prerequisite for selectively deposition of $\mathrm{Ru}$ atoms on Pt atoms. The atomic resolution HAADF-STEM images illustrate that a dimer-like structure was successfully synthesized by the designed ALD process (Fig. 2a-c, and Supplementary Fig. 3). The two atoms in the dimer show different contrast (Fig. 2d), which indicates the dimer-like structure is composed of two different elements (in this case are $\mathrm{Pt}$ and $\mathrm{Ru}$ atoms). In addition, the appearance of the $\mathrm{Pt}-\mathrm{Ru}$ dimer structure is further confirmed by the X-ray absorption spectroscopy (XAS) results that discussed below. Although the dimer structure is not very uniform around the sample, the ratio of dimer structures is around 70\% (Fig. 2e), indicating the significant amount of this type of structures in the material prepared. The $\mathrm{Pt}-\mathrm{Ru}$ bonding of the dimers was statistically analysed and showed a distance of $0.24 \pm 0.04 \mathrm{~nm}$ (Fig. 2f). The influence of the ALD temperature for the deposition of Pt and $\mathrm{Ru}$ was also investigated. With a decrease in the Pt ALD process temperature from $250^{\circ} \mathrm{C}$ to $200^{\circ} \mathrm{C}$ and $150{ }^{\circ} \mathrm{C}$, ICP-OES results indicated that the $\mathrm{Pt}$ loading amounts on NCNT reduced from 0.9 to 0.65 and $0.42 \mathrm{wt} \%$, respectively. Upon deposition of $\mathrm{Ru}$ on these three samples with different Pt loading at $270{ }^{\circ} \mathrm{C}$, the $\mathrm{Ru}$ loadings was systematically reduced from $0.31 \%$ to 0.23 and $0.14 \mathrm{wt} \%$ (Fig. 2g). These results also directly demonstrate the selective deposition of $\mathrm{Ru}$ on $\mathrm{Pt}$ and the formation of dimer structures.

X-ray absorption fine structure of Pt-Ru dimers. We carried out XAS measurements to further investigate the electronic environment of $\mathrm{Pt}$ and $\mathrm{Ru}$ atoms in dimers. Figure $3 \mathrm{a}, \mathrm{b}$ shows the normalized XANES spectra at $\mathrm{Pt}_{3}$ and $\mathrm{L}_{2}$ edge, respectively. By qualitative and quantitative analysis of the $\mathrm{Pt}_{2}$ and $\mathrm{L}_{3}$ edges white lines $(\mathrm{WL}) \mathrm{s}$, the detailed Pt d state electronic structure can be revealed ${ }^{37}$. It is apparent that $\mathrm{Pt}$ foil exhibits a strong $\mathrm{L}_{3}$-edge $\mathrm{WL}$ and a very weak $\mathrm{L}_{2}$-edge $\mathrm{WL}$ due to the large spin orbit coupling of the $5 \mathrm{~d}$ and an even distribution of the $5 d_{5 / 2}$ and $5 d_{3 / 2}$ densities of states just above the fermi level in metallic Pt; while both the dimer and single atoms exhibit substantial WL intensity at $\mathrm{Pt} \mathrm{L}_{3}$ and $\mathrm{L}_{2}$ edges. In addition, the $\mathrm{Pt}-\mathrm{Ru}$ dimers have the most intense WL among the three spectra. Note that the integrated area under the WL peak of $\mathrm{Pt}_{2,3}$-edge can directly reflect the unoccupied density of states of the Pt $5 \mathrm{~d}$ orbitals. With the increase in the $\mathrm{L}_{2,3}$-edge WL intensity, the number of electrons in the occupied $\mathrm{d}$ band decreases. In addition, the first derivative of the XANES spectrum shows the threshold energy $\mathrm{E}_{0}$ for the $\mathrm{Pt}$ 


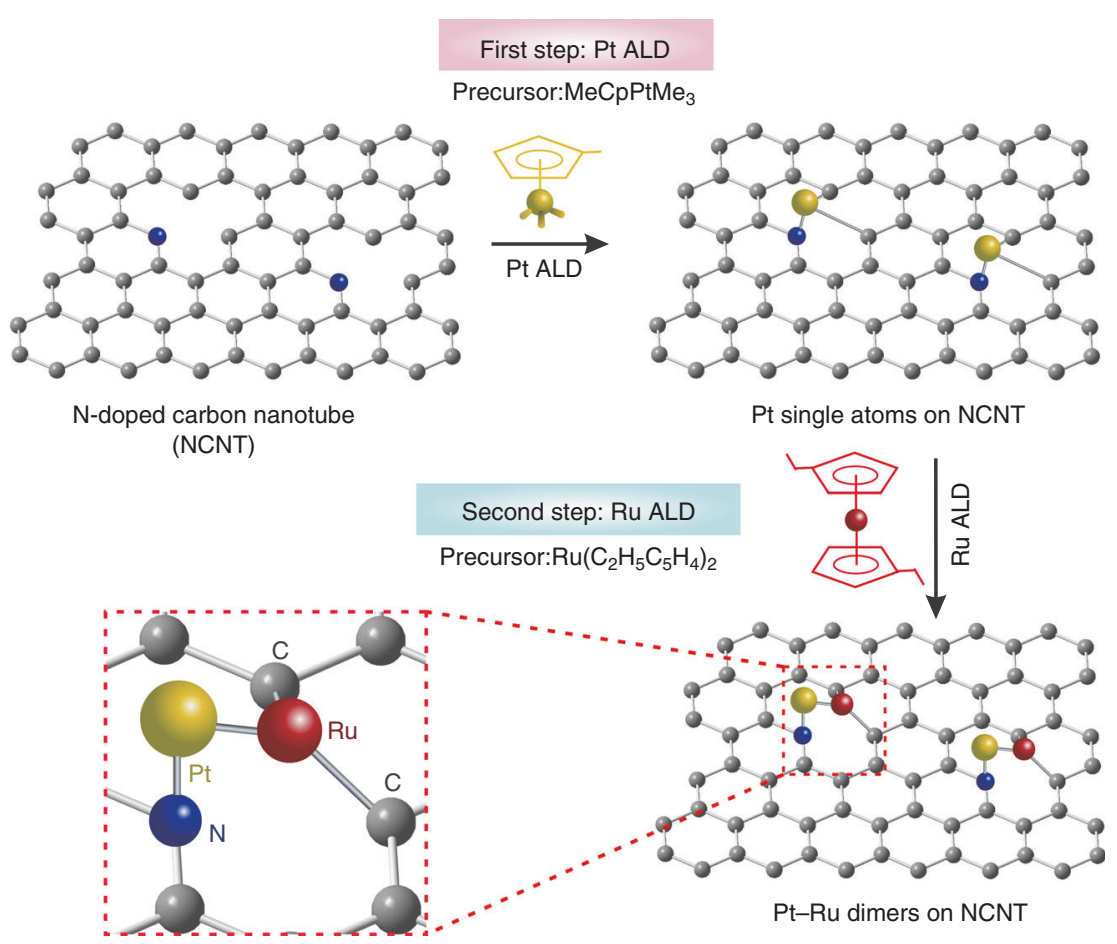

Fig. 1 Schematic illustration of ALD synthesis of Pt-Ru dimers on nitrogen-doped carbon nanotubes (NCNTs). Firstly, the Pt single atoms were deposited by using $\mathrm{MeCpPtMe}_{3}$ as the precursor. Then the Pt-Ru dimers were prepared by selective deposition of Ru atoms on Pt single atoms. Gray: $\mathrm{C}$, Blue: $\mathrm{N}$, yellow: Pt, red: $\mathrm{Ru}$

single atoms, Pt-Ru dimers and Pt foil (Supplementary Fig. 4). Among the three samples, the $\mathrm{E}_{0}$ for $\mathrm{Pt}$ single atoms and $\mathrm{Pt}-\mathrm{Ru}$ dimer structure are 11565.5 and $11565.9 \mathrm{eV}$, which are much higher than that of $11564.0 \mathrm{eV}$ of $\mathrm{Pt}$ foil. This result means that $\mathrm{Pt}$ is depleted in $\mathrm{d}$ charge. To further explore the implication of the electronic information of $5 \mathrm{~d}$ states in $\mathrm{Pt}$, we quantitatively analyzed the occupancy of the Pt $5 \mathrm{~d}$ states in each sample based on a reported method ${ }^{38}$. Table 1 summarizes the detailed information of $\mathrm{Pt}_{\mathrm{L}^{-}}$and $\mathrm{Pt} \mathrm{L}_{2}$-edge threshold. From the analysis, the $\mathrm{Pt}-\mathrm{Ru}$ dimers have the highest total unoccupied density of states of Pt $5 \mathrm{~d}$ character (1.09), while the Pt $5 \mathrm{~d}$ character of Pt foil is only 0.70 . Several previous studies showed that the high unoccupied density of $\mathrm{Pt} \mathrm{d}$-orbitals played an important role in enhancing the activity of catalysts ${ }^{17,18,39}$.

In addition to XANES spectra, the EXAFS spectrum was analyzed to investigate the local structure environment of Pt. Figure $3 c$ shows the magnitude of Fourier transforms (FT) of the $\mathrm{Pt}$ EXAFS for Pt single atoms, Pt-Ru dimers and Pt foil. The EXAFS R space curve attributes the FT magnitude peak at $1.6 \AA$ to $\mathrm{Pt}-\mathrm{C} / \mathrm{N} / \mathrm{O}$ upon which $\mathrm{Pt}$ is anchored. To exclude the $\mathrm{Pt}-\mathrm{O}$ bond, we tested the XANES and EXAFS spectrum of $\mathrm{PtO}_{2}$ (Supplementary Fig. 5). As shown in the FT spectra from EXAFS of the $\mathrm{PtO}_{2}$, two obvious peaks can be observed at around 2.7 and $3.3 \AA$, respectively. However, in the Pt single atom sample, we did not observe a peak at 2.7 either $3.3 \AA$ (Fig. 3c). This result indicates that no $\mathrm{Pt}-\mathrm{O}$ formed in $\mathrm{Pt}$ single atoms. In addition, previous studies showed that the metal single atoms can be stabilized by bonding with $\mathrm{C}$ and $\mathrm{N}$ on the substrates. ${ }^{40-43}$ Thus, we concluded that the peak at $1.6 \AA$ is attributed to Pt-N/Pt-C bond. The peak at $2.6 \AA$ can be ascribed to the Pt-Pt or Pt-Ru bonding. For the Pt foil, the first shell FT peak is resolved at $2.6 \AA$, corresponding to $\mathrm{Pt}-\mathrm{Pt}$ bonding. For the $\mathrm{Pt}-\mathrm{Ru}$ dimers, in addition to an obvious $\mathrm{Pt}-\mathrm{N} / \mathrm{Pt}-\mathrm{C}$ peak, a relative weak feature resolved at around $2.6 \AA$. As the dimer structure is prepared from $\mathrm{Pt}$ single atoms, the peak at $2.6 \AA$ is arising from the $\mathrm{Pt}-\mathrm{Ru}$ bonding.
XAS was also used to investigate the Ru electronic structure change in the Pt-Ru dimer catalysts (Fig. 3d). The XANES Ru K edge of $\mathrm{Pt}-\mathrm{Ru}$ dimer sample shows a relatively broader curve features compared to that of $\mathrm{Ru}$ metal. The Ru K-edge of the dimer does not exhibit the beating of oscillations characteristic of the hexagonal $\mathrm{Ru}$ metal. A simple boarded sinusoidal oscillation indicates that there is no long range order with the presence of a $\mathrm{Pt}-\mathrm{Ru}$ pair plus substrate low $\mathrm{z}$ atoms. In addition, a higher energy shift of the edge for Pt-Ru dimers compared to Ru metal can be observed from the Ru K XANES spectra, which indicates the charge redistribution also in favor of a charge depletion at the $\mathrm{Ru}$ site relative to $\mathrm{Ru}$ metal. The positive $\mathrm{E}_{0}$ shift of $\mathrm{Ru}$ is due to the bonding between $\mathrm{Ru}$ atoms and $\mathrm{C}$ on the substrates. The fact that both $\mathrm{Pt}_{\mathrm{L}_{3}}$-edge and $\mathrm{Ru} \mathrm{K}$-edge show a small threshold shift is due to the combined interaction of the Pt-Ru dimers with the substrate. The FT of the EXAFS region for Pt-Ru dimers and $\mathrm{Ru}$ foil are shown in Fig. 3e. The Pt-Ru dimers exhibited an obvious $\mathrm{Ru}-\mathrm{C}$ peak at around $1.6 \AA$ and a relative weak peak at around $2.8 \AA$. The peak below $2 \AA$ can be assigned to bonds formed between $\mathrm{Ru}$ and $\mathrm{C}$. The small peak at $2.8 \AA$ is attributed to the $\mathrm{Pt}-\mathrm{Ru}$ scattering by $\mathrm{R}$ space curve fitting (see more detailed analysis below). It should noted that since the $\mathrm{k}$ dependence of the backscattering amplitude in these heavy atoms exhibit oscillations in $\mathrm{k}$ space, the FT of the EXAFS is no longer a simple symmetric peak as in low $\mathrm{z}$ scattering atoms like $\mathrm{C}$ or $\mathrm{N}$ where the $k$ dependence of $f(k, \pi)$ is monotonic.

Electrocatalytic performance of Pt-Ru dimers towards HER. Cyclic voltammograms (CV) of the $\mathrm{Pt}-\mathrm{Ru}$ dimers, $\mathrm{Pt}$ single atoms and commercial $\mathrm{Pt} / \mathrm{C}$ were recorded in $0.5 \mathrm{M} \mathrm{H}_{2} \mathrm{SO}_{4}$ at a scanning rate of $50 \mathrm{mV} \mathrm{s}^{-1}$. As the Pt loading of Pt-Ru dimers and $\mathrm{Pt}$ single atoms is extremely low, no obvious hydrogen adsorption/ desorption peak is observed (Supplementary Fig. 6). As Ru in the dimer structure can adsorb and desorb O more easily through an oxidation-reduction process than $\mathrm{Pt}$, the $\mathrm{CV}$ curve in 


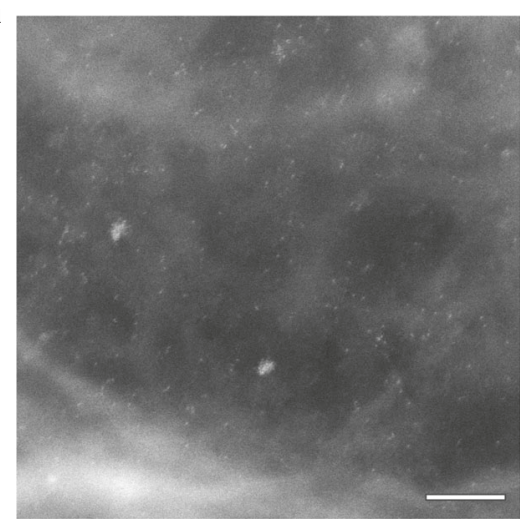

e

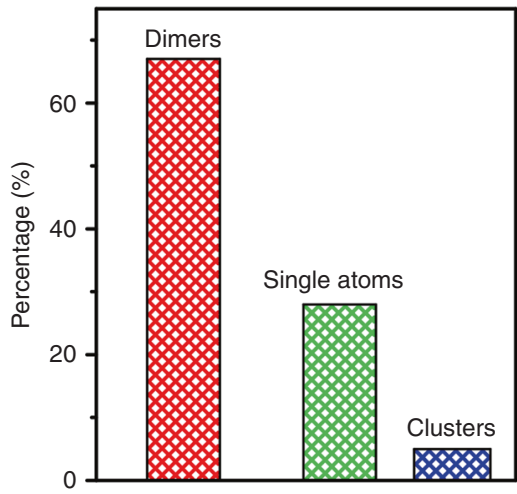

b

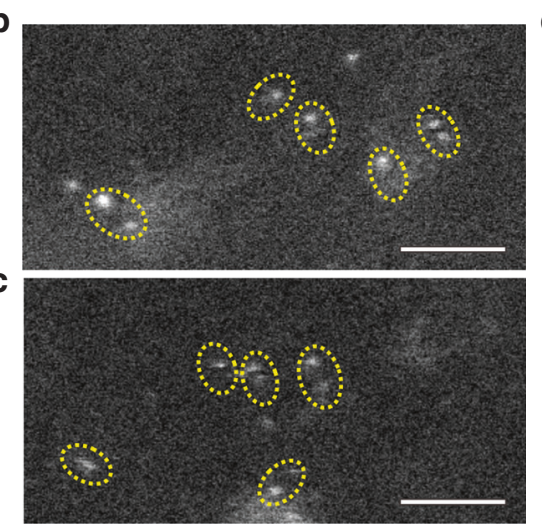

f

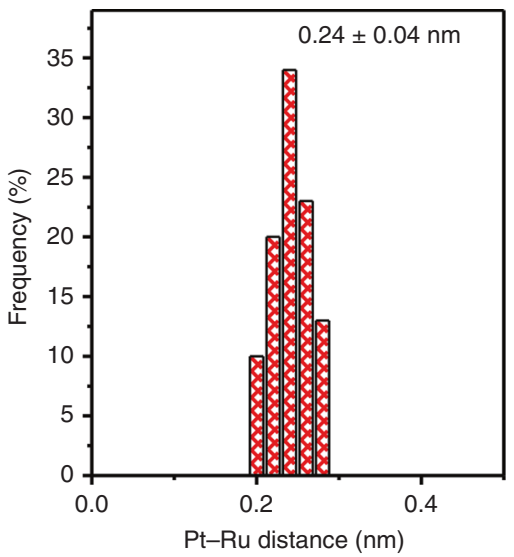

d

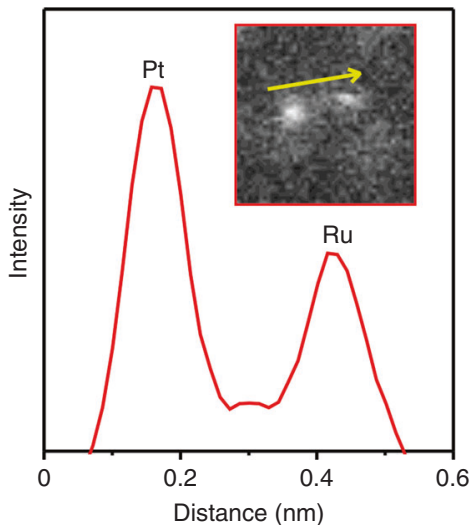

g

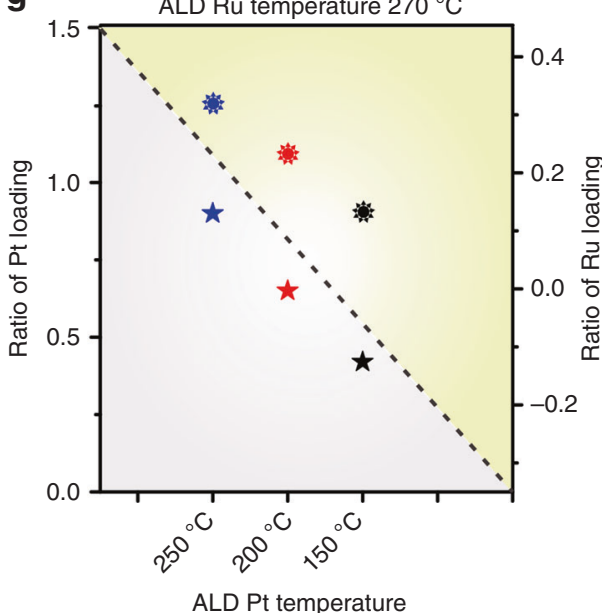

Fig. 2 Characterizations of Pt-Ru dimers. a-c Aberration-corrected HAADF-STEM images of Pt-Ru dimers/NCNTs. Scale bars, 5 nm (a); 1 nm (b, c). The slowly varying contrast is due to the changes in the thickness of the substrate. $\mathbf{d}$ The intensity profile obtained on one individual Pt-Ru dimer. e Distribution histogram showing the ratio between dimers, single atoms and clusters. We determined the percentage of dimers by counting 200 clusters. $\mathbf{f}$ Pt-Ru distance in the observed Pt-Ru dimers. $\mathbf{g}$ The ratio of Pt and Ru loading in Pt-Ru dimers/NCNTs, which were obtained under different ALD conditions

Supplementary Fig. 6b exhibited a weak O adsorption/desorption peak. Figure 4a shows the HER curves of the catalysts, which were measured by conducting linear sweep voltammetry measurements in $0.5 \mathrm{M} \mathrm{H}_{2} \mathrm{SO}_{4}$ at room temperature. To directly compare the activity of Pt-Ru dimers, Pt single atoms and commercial Pt/ $\mathrm{C}$ catalysts, we normalized the current density with the geometric area of the electrode to obtain the specific activity for each catalyst (Supplementary Fig. 7). The result indicates that both the Pt-Ru dimers and Pt single atoms exhibit comparable specific activity with $\mathrm{Pt} / \mathrm{C}$. In addition, the $\mathrm{Pt}-\mathrm{Ru}$ dimers exhibit better HER activity than Pt single atoms. We further calculated the mass HER activities based on the mass loading at the overpotential of $0.05 \mathrm{~V}$ (The metal mass loadings for $\mathrm{Pt} / \mathrm{C}$, $\mathrm{Pt}$ single atoms, and $\mathrm{Pt}-\mathrm{Ru}$ dimers on the electrode are $61.2,1.34$ and $1.67 \mu \mathrm{g} \mathrm{cm}^{-2}$, respectively). The Pt-Ru dimers shows the mass activity of $23.1 \mathrm{~A} \mathrm{mg}^{-1}$ at the overpotential of $0.05 \mathrm{~V}$, which is 54 fold greater than the $\mathrm{Pt}$ / $\mathrm{C}$ catalysts $\left(0.43 \mathrm{~A} \mathrm{mg}^{-1}\right)$. Furthermore, the mass activity of $\mathrm{Pt}-\mathrm{Ru}$ dimers exceeds most of the other state-of-the-art Pt-based catalysts (Supplementary Table 1). These results indicate that the $\mathrm{Pt}-\mathrm{Ru}$ dimer structures can effectively improve the HER activity in contrast to single atoms and NPs. We also employed Tafel plots to illustrate the HER kinetics of the catalysts. As shown in Supplementary Fig. 8, the Tafel slope of Pt-Ru dimers, Pt single

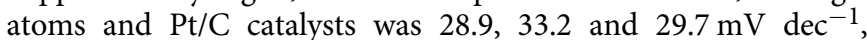
respectively. Empirically, the Tafel slope value can attributed to the slow atomic combination to form $\mathrm{H}_{2}$. It should be noted that the Pt SA is different from the Pt surface, and the former could adsorb more than one hydrogen atom on the one isolated atom, and each $\mathrm{Pt}$ atom of the later typically adsorbs one hydrogen atom at the surface ${ }^{18,30,31}$. Thus the Pt SA can process the HER process on the isolated $\mathrm{Pt}$ atom through the Tafel half reaction $\left(\mathrm{H}_{\mathrm{ads}}+\mathrm{H}_{\mathrm{ads}} \rightarrow \mathrm{H}_{2}\right)$.

To evaluate the durability of the Pt-Ru dimers and Pt SACs, accelerated degradation tests (ADTs) were adopted between +0.4 and $-0.15 \mathrm{~V}$ (versus RHE) at $100 \mathrm{mV} \mathrm{s}^{-1}$ for 5000 cyclic voltammetry sweeps. As shown in Fig. $4 \mathrm{c}$, the polarization curve of $\mathrm{Pt}-\mathrm{Ru}$ dimers after ADT tests exhibited a very similar activity as the initial test. The HER activity at the overpotential of $0.05 \mathrm{~V}$ only showed a 5\% loss for the Pt-Ru dimers (Fig. 4d). While, the Pt SACs showed a $9 \%$ loss at the overpotential of $0.05 \mathrm{~V}$ after ADT test. The Pt/C catalysts exhibited the worst stability, and the activity dropped $28 \%$ after 5000 cycles at an overpotential of 0.05 V (Supplementary Figs. 9-11). In addition, the TEM images of the post-testing $\mathrm{Pt}-\mathrm{Ru}$ dimer catalysts indicated that the dimer structure is stable after the durability test (Supplementary Fig. 12). The different intense of two atoms in one dimer indicate the existence of dimer structure. We also carried out the XAS test for the dimer structures after HER test. The XANES spectrum of Pt has almost no change. In the K2-weighted magnitude of FT spectra from EXAFS spectrum, a small peak at $2.8 \AA$ attributed to 

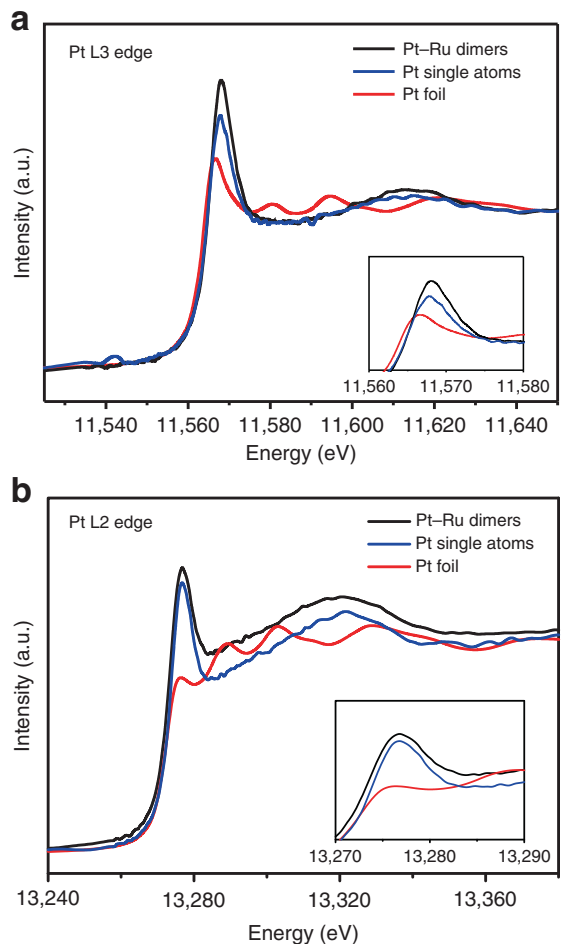
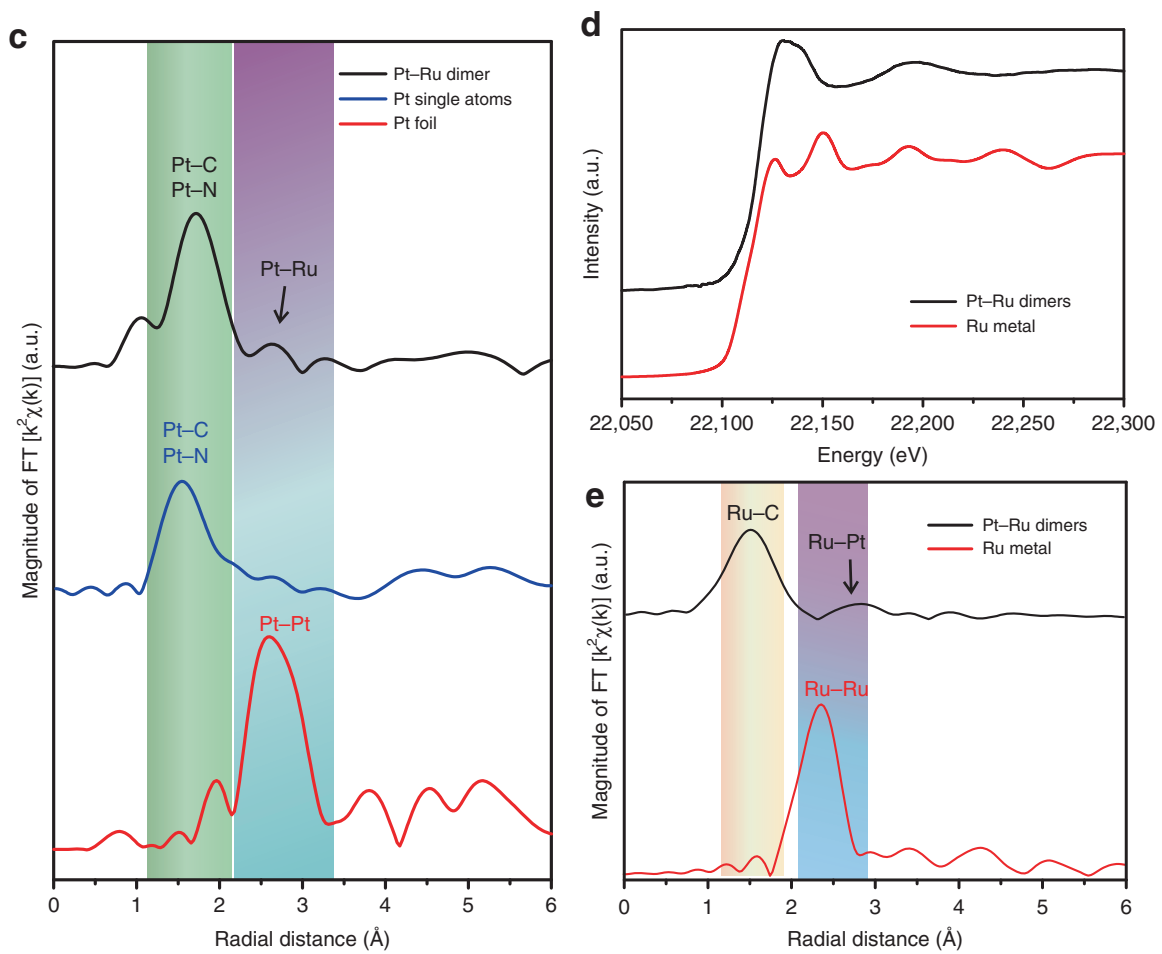

Fig. 3 X-ray absorption studies of the Pt-Ru dimers, Pt single atoms and Pt foil. a, b The normalized XANES spectra at the Pt L3-edge and L2-edge of the Pt-Ru dimers, Pt single atoms and Pt foil. c corresponding K2-weighted magnitude of Fourier transform spectra from EXAFS of the Pt-Ru dimers, Pt single atoms and Pt foil. d The normalized XANES spectra at the Ru K-edge and e corresponding K2-weighted magnitude of Fourier transform spectra from EXAFS of the Pt-Ru dimers and Ru metal

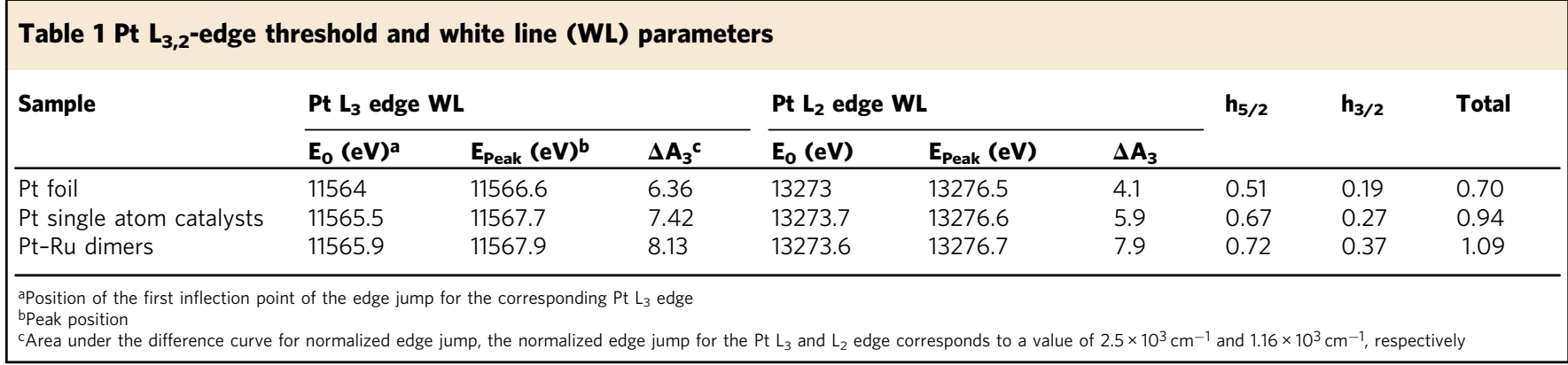

the Pt-Ru scattering can still be observed (Supplementary Fig. 13). For the Ru XAS spectra, three XANES features A, B and C can be reproduced, indicating the maintenance of the $\mathrm{Pt}-\mathrm{Ru}$ dimer structure (Supplementary Fig. 14). We also carried out the longterm stability of the Pt-Ru dimers, $\mathrm{Pt}$ single atoms and commercial Pt/C by extended electrolysis at fixed current density of $10 \mathrm{~mA} \mathrm{~cm}^{-2}$ for $10 \mathrm{~h}$. Supplementary Fig. 15 shows that the $\mathrm{Pt}-\mathrm{Ru}$ dimers and $\mathrm{Pt}$ single atoms exhibit much better HER stability than Pt/C catalysts. Compared to the $95.1 \mathrm{mV}$ potential drop for the $\mathrm{Pt} / \mathrm{C}$, there are only 19.6 and $56.9 \mathrm{mV}$ potential drop for Pt-Ru dimers and Pt single atoms, respectively. Thanks to the strong interaction between $\mathrm{Pt}$ atoms with the $\mathrm{N}$-site, both $\mathrm{Pt}-\mathrm{Ru}$ dimers and $\mathrm{Pt}$ single atoms show better stability than the $\mathrm{Pt} / \mathrm{C}$ catalysts.

Identifying the active sites of dimers by DFT calculations. We performed DFT calculations to deeper understand the origin of the HER activity of Pt-Ru dimers. Considering the Ru atoms were deposited after the Pt SAs were formed, most of the N-sites have been occupied by the Pt atoms. Thus the Ru atoms could only either bond with $\mathrm{Pt}$ to form $\mathrm{Pt}-\mathrm{Ru}$ dimer or form $\mathrm{Ru}-\mathrm{Ru}$ dimer. The adsorption energies of $\mathrm{Ru}-\mathrm{Ru}$ dimer on the perfect site and $\mathrm{Pt}-\mathrm{Ru}$ dimer on the $\mathrm{N}$-doped site were calculated to be -1.3 and $-4.87 \mathrm{eV}$, which indicates that the Ru prefers to form the $\mathrm{Pt}-\mathrm{Ru}$ dimer instead of $\mathrm{Ru}-\mathrm{Ru}$ dimer. In addition, as we clearly identify the $\mathrm{Pt}-\mathrm{Ru}$ atomic pairs from HAADF-STEM images and $\mathrm{Pt}-\mathrm{Ru}$ bonding from EXAFS spectra, the following first-principle calculations were carried out using one $\mathrm{Pt}-\mathrm{Ru}$ dimer on the $\mathrm{N}$-doped graphene to identify reactivity of the dimer. The EXAFS R space curve fitting and DFT model guided $\mathrm{Ru} \mathrm{K}$ edge XANES theoretical modeling demonstrate the validity of the DFT models, which will be discussed below. We explored how the $\mathrm{H}$ adsorption evolves on the Pt-Ru dimer step by step, and the different numbers of $\mathrm{H}$ adsorption on the $\mathrm{Pt}-\mathrm{Ru}$ dimer were examined. As for one hydrogen atom, it prefers to adsorb on the $\mathrm{Ru}$ atom at the adsorption energy of $-3.3 \mathrm{eV}$ rather than the Pt atom $(-2.5 \mathrm{eV})$. It should be noted that the second $\mathrm{H}$ is not so easy to adsorb on the Pt-Ru dimer compared with the first one, 

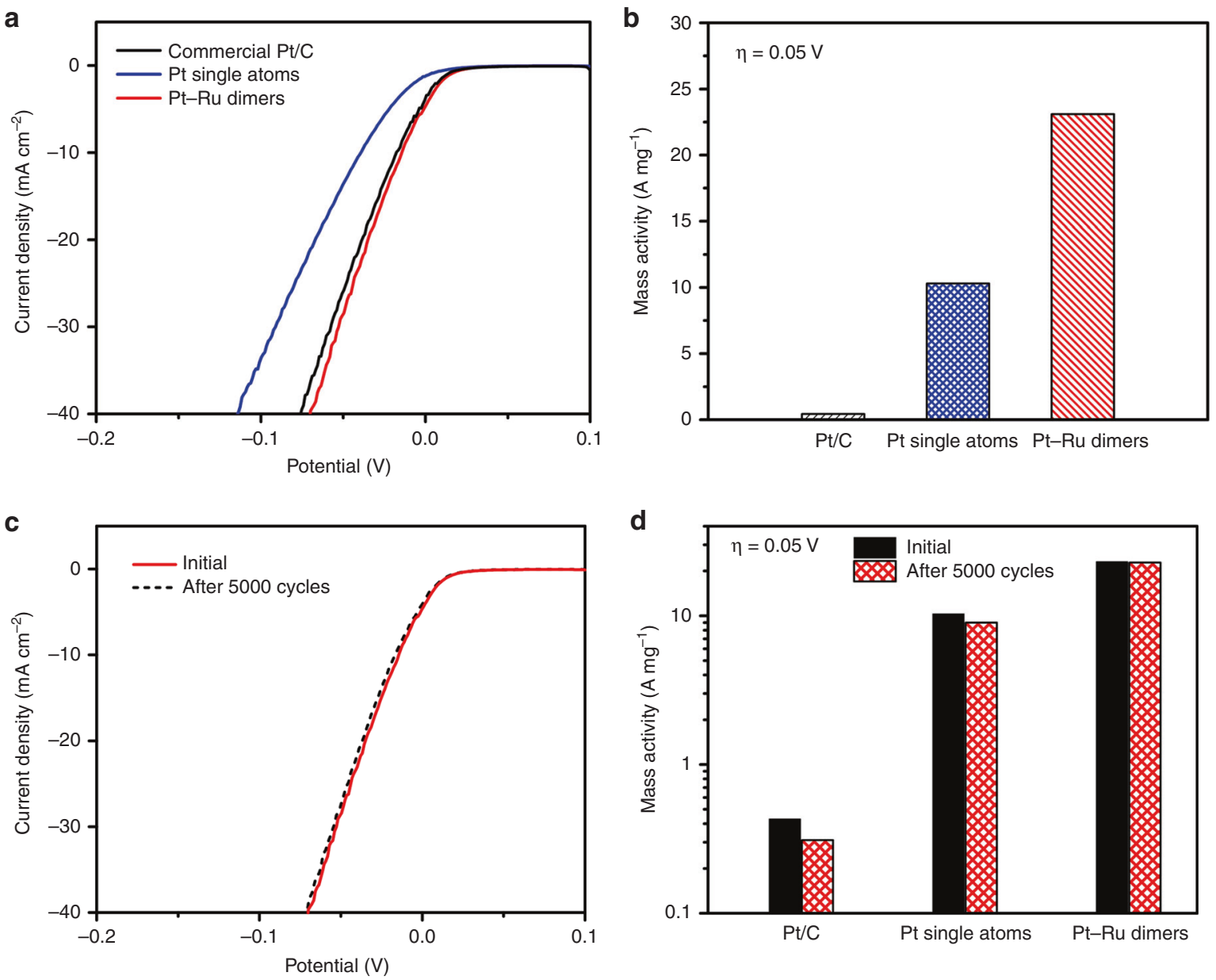

Fig. 4 Electrocatalytic performance of Pt-Ru dimers towards HER. a The HER polarization curves recorded on Pt-Ru dimers, Pt single atoms and Pt/C catalysts. b Normalized mass activity at $0.05 \mathrm{~V}$ of Pt-Ru dimers, Pt single atoms and Pt/C catalysts. c Durability measurement of the Pt-Ru dimers catalysts. $\mathbf{d}$ Normalized mass activity at $0.05 \mathrm{~V}$ of Pt-Ru dimers, Pt single atoms and Pt/C catalysts before and after durability tests. The Pt mass loadings for Pt/C, Pt single atoms, and Pt-Ru dimers are 61.2, 1.34 and $1.24 \mu \mathrm{gm}^{-2}$, respectively

while with the further increasing number of the hydrogen atoms, the $\mathrm{H}$ adsorption becomes favorable again, which should be related with the change of electronic structure for $\mathrm{Pt}-\mathrm{Ru}$ dimer.

Different from the NPs ${ }^{18}$, each $\mathrm{Pt}$ or $\mathrm{Ru}$ atom of dimer could adsorb more than one hydrogen atoms. Thus, we further studied the total hydrogen number of $\mathrm{H}$ adsorption on $\mathrm{Pt}-\mathrm{Ru}$, which was gradually increased from 2 to 6 , and the results were shown in Fig. 5 and Supplementary Table 2. Interestingly, after the first step, the hydrogen atoms first adsorb on the Pt side one by one, after three hydrogen atoms adsorb on Pt side and one hydrogen on $\mathrm{Ru}$ side, the next one prefers to stay on the $\mathrm{Ru}$ atom in sequence. By repeating this process, the maximum number of adsorbed $\mathrm{H}$ atoms on either $\mathrm{Pt}$ and $\mathrm{Ru}$ atoms reach 3 . In the following, we referred it as $\operatorname{Pt}(\mathrm{nH}) \mathrm{Ru}(\mathrm{mH})$. As shown in Fig. 5a, before the final step, two possible mediate structures, $\mathrm{Pt}(3 \mathrm{H}) \mathrm{Ru}$ $(2 \mathrm{H})$ and $\mathrm{Pt}(2 \mathrm{H}) \mathrm{Ru}(3 \mathrm{H})$, could be formed, and the $\mathrm{Pt}(3 \mathrm{H}) \mathrm{Ru}(2 \mathrm{H})$ is the energetically more stable. The bond distance between $\mathrm{Pt}$ and $\mathrm{Ru}$ atoms increases from $2.38 \AA(\mathrm{Pt}(0 \mathrm{H}) \mathrm{Ru}(0 \mathrm{H}))$ to $2.75 \AA$ $(\mathrm{Pt}(2 \mathrm{H}) \mathrm{Ru}(3 \mathrm{H}))$ with the increase of the $\mathrm{H}$ adsorption, while it becomes $2.72 \AA$ for the $\operatorname{Pt}(3 \mathrm{H}) \mathrm{Ru}(2 \mathrm{H})$, which is about $0.1 \AA$ longer than the last step. To understand the stability of the pure $\mathrm{Pt}-\mathrm{Ru}$ and $\mathrm{Pt}-\mathrm{Ru}$ with $6 \mathrm{H}$ on the $\mathrm{N}$-doped graphene, the first principles molecular dynamics (FPMD) were carried out for 5 ps with the target temperature of $300 \mathrm{~K}$. The results show that both $\mathrm{Pt}-\mathrm{Ru}$ dimer with and without the six $\mathrm{H}$ were stable, and no big structure change occurred during this process, which further confirm the stability of the Pt-Ru dimer (Supplementary Fig. 16).

The calculated hydrogen adsorption Gibbs free energies $\left(\Delta G_{H}\right)$ of the $\mathrm{Pt}-\mathrm{Ru}$ dimer were performed to examine the activity of the HER for different number of $\mathrm{H}$ atoms, and the results for typical configurations are shown in Fig. 5b. When one hydrogen atom adsorbs on both $\mathrm{Ru}$ and $\mathrm{Pt}$ sides of the $\mathrm{Pt}-\mathrm{Ru}$ dimer, the corresponding Gibbs free energy for $\mathrm{Pt}(1 \mathrm{H}) \mathrm{Ru}(1 \mathrm{H})$ is about $-1 \mathrm{eV}$. When another hydrogen adsorbs on the dimer, the corresponding Gibbs free energy for $\operatorname{Pt}(2 \mathrm{H}) \mathrm{Ru}(1 \mathrm{H})$ becomes about $0.6 \mathrm{eV}$. This means that the hydrogen atoms are anchored on $\mathrm{Ru}$ atom steadily or hard to detach from either $\mathrm{Ru}$ or $\mathrm{Pt}$ atom at this stage. As for the last step (see Fig. 5), three hydrogen atoms connect with the $\mathrm{Pt}$ atom $(3 \mathrm{H}-\mathrm{Pt})$, and three bonds with $\mathrm{Ru}$ atom $(3 \mathrm{H}-\mathrm{Ru})$. The $\mathrm{Ru}$ atom exhibits the low $\Delta G_{H}$ of $0.01 \mathrm{eV}$ through the pathway of $\mathrm{Pt}$ $(3 \mathrm{H}) \mathrm{Ru}(3 \mathrm{H}) \rightarrow \mathrm{Pt}(3 \mathrm{H}) \mathrm{Ru}(2 \mathrm{H})$, which clearly indicates that the hydrogen atom becomes easy to detach from $\mathrm{Ru}$ when the maximum coverage of $6 \mathrm{H}$ is reached. The corresponding $\Delta G_{H}$ is $0.01 \mathrm{eV}$, which is even smaller than that of the single atom $\mathrm{Pt}$ (see Supplementary Fig. 17 and Supplementary Table 3) ${ }^{44}$. Meanwhile, the calculated $\Delta \mathrm{G}_{\mathrm{H}}$ of Pt-Pt dimer is about $-0.14 \mathrm{eV}$ (Supplementary Fig. 18), which is quite close to that the bulk one, inferior to that of $\mathrm{Pt}-\mathrm{Ru}$ as well. This suggests that the $\mathrm{Ru}$ of $\mathrm{Pt}-\mathrm{Ru}$ dimer should play the vital role in the HER reaction although Pt NPs generally exhibit high activity for HER. 

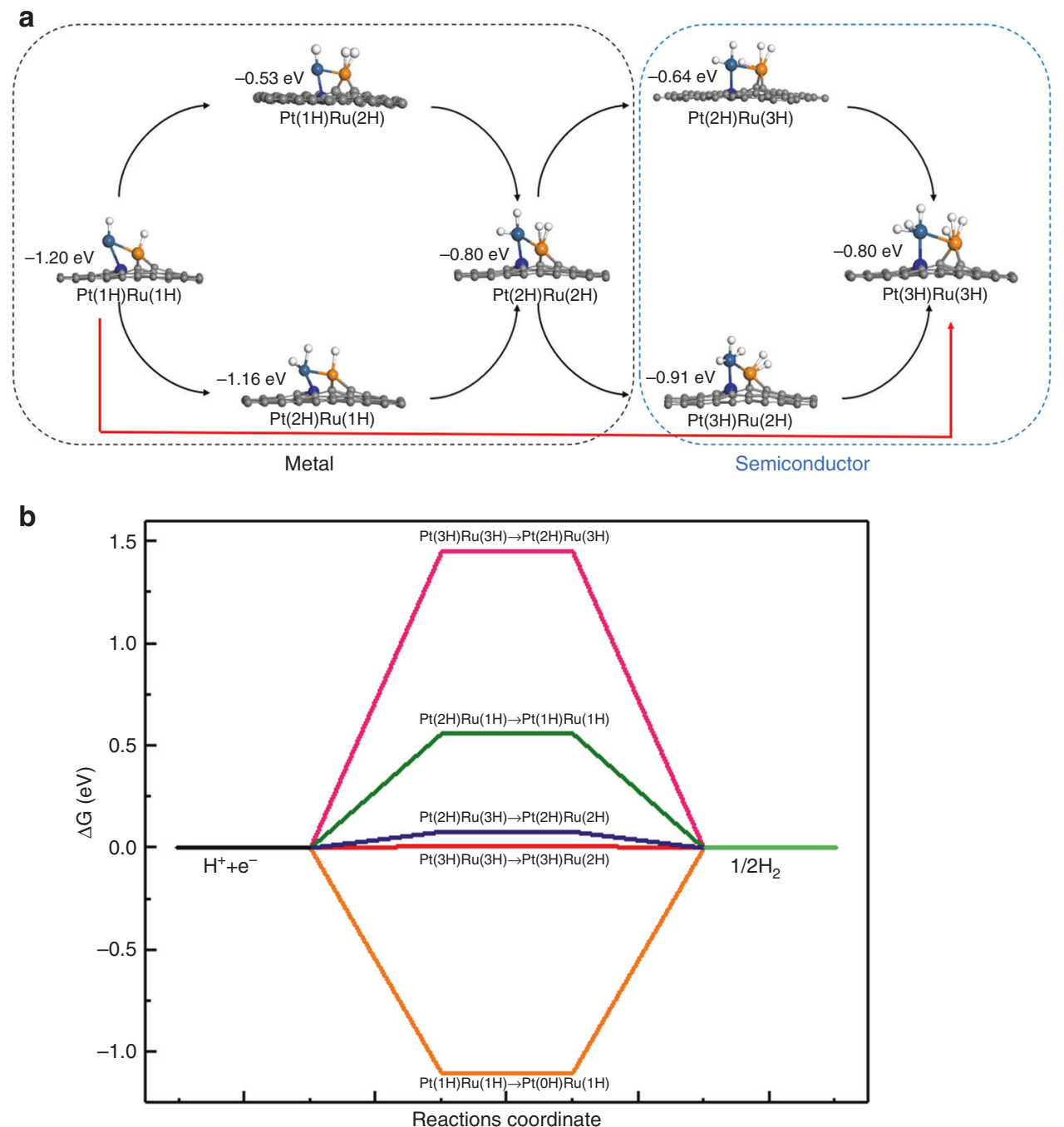

Fig. 5 Hydrogen adsorption configurations on the Pt-Ru dimer and the $\Delta G_{H}$ for different coverages of typical configurations. a The atom structures of different $\mathrm{H}$ adsorption along with the adsorption energies. $\mathbf{b}$ The schematic of $\Delta G_{H}$ for the different hydrogen coverages of typical configurations. For each coverage, all the possible pathways were considered, and the lowest $\Delta G_{H}$ for each coverage was typically shown, except we noted. Here, $\mathrm{Pt}(\mathrm{nH}) \mathrm{Ru}(\mathrm{mH})$ represents $\mathrm{n} \mathrm{H}$ atoms adsorbed on $\mathrm{Pt}$ and $\mathrm{m} \mathrm{H}$ atoms on $\mathrm{Ru}$. Orange, dark blue, light blue and gray balls represent the $\mathrm{Ru}, \mathrm{Pt}, \mathrm{N}$ and $\mathrm{C}$ atoms, respectively

In order to further understand why the dimer exhibits the superior activity, the detailed electronics structures for the different stages are explored. The partially density of states (PDOS) for both the $\mathrm{Pt}$ and $\mathrm{Ru}$ atoms are examined, and the results are shown in Fig. 6a and Supplementary Figs. 19-22. As shown in Supplementary Fig. 19, before the hydrogen adsorption, both $\mathrm{Pt}$ atom and $\mathrm{Ru}$ atom of dimer exhibits unoccupied states, which should origin from the bonding between metal ion and $\mathrm{C} /$ $\mathrm{N}$ atoms. Meanwhile such results also agree well with our XAS experiments as discussed above. With the increase of the hydrogen adsorption, the calculated PDOS also suggested that both the $\mathrm{Pt}$ and $\mathrm{Ru}$ gradually lost the metallic, resulting more unoccupied states, when the two hydrogen atoms adsorb on both $\mathrm{Pt}$ and $\mathrm{Ru}(\mathrm{Pt}(2 \mathrm{H})-\mathrm{Ru}(2 \mathrm{H})$ ), respectively (see Supplementary Fig. 20 and Fig. 5a). As shown in Fig. 5a and Supplementary Table 2, the $\Delta G_{H}$ becomes small after the electronic structures of both $\mathrm{Pt}$ and $\mathrm{Ru}$ become semiconductor. Meanwhile with the increase of the hydrogen adsorption, the $\Delta G_{H}$ is further reduced, thus the electronic structure of $\mathrm{Pt}-\mathrm{Ru}$ dimer under the hydrogen adsorption plays a vital role in modulating the HER activity of Pt-Ru dimer.
Considering the Pt-Ru atom show the small $\Delta G_{H}$ under the high hydrogen coverage $(\mathrm{Pt}(3 \mathrm{H}) \mathrm{Ru}(3 \mathrm{H}))$, the corresponding oxidation states for $\mathrm{Pt}$ and $\mathrm{Ru}$ are explored based on the occupation number and PDOS. Before Pt-Ru dimer reaches the best HER activity, the $\mathrm{Ru}$ atom interacts with two $\mathrm{C}$ atoms of the substrate and two hydrogen atoms and the Pt bonds with one $\mathrm{N}$ atoms and three hydrogen atoms $(\mathrm{Pt}(3 \mathrm{H}) \mathrm{Ru}(2 \mathrm{H}))$. The corresponding crystal field of the $\mathrm{Pt}$ and $\mathrm{Ru}$ are octahedral and tetrahedral (see Fig. 6b-d), respectively. In this situation, the $\mathrm{d} x y$, $\mathrm{d} z^{2}, \mathrm{~d} x^{2}-y^{2}$, and $\mathrm{dxz}$ are half-filled, and the dyz orbital is fully unoccupied, thus the $\mathrm{Ru}$ atom corresponds to $4+$ for $\mathrm{Pt}(3 \mathrm{H}) \mathrm{Ru}$ $(2 \mathrm{H})$. As for the $\mathrm{Pt}$, the $\mathrm{d} x^{2}-y^{2}$ is half-filled, $\mathrm{d} z^{2}$ is fully unoccupied and all other orbital are occupied, thus the Pt is $3+$. In this situation, the hydrogen atom on $\mathrm{Ru}$ owning the smaller $\Delta G_{H}$ mainly stays in the direction of the dxz.

With the further $\mathrm{H}$ adsorption on the $\mathrm{Ru}$ atom from 2 to 3, the $\mathrm{Ru}$ is oxidized from $4+$ to $5+$ and $\mathrm{Pt}$ is reduced from $3+$ to $2+$. In this process, the bond distance between the Pt-Ru dimer decreases from 2.72 to $2.63 \AA$, which results in the electron redistribution between Pt-Ru dimer. The $\mathrm{d} x^{2}-y^{2}$ of Pt becomes fully-occupied, and the $\mathrm{Pt}$ is reduced to $2+$. Meanwhile, the bond 
a

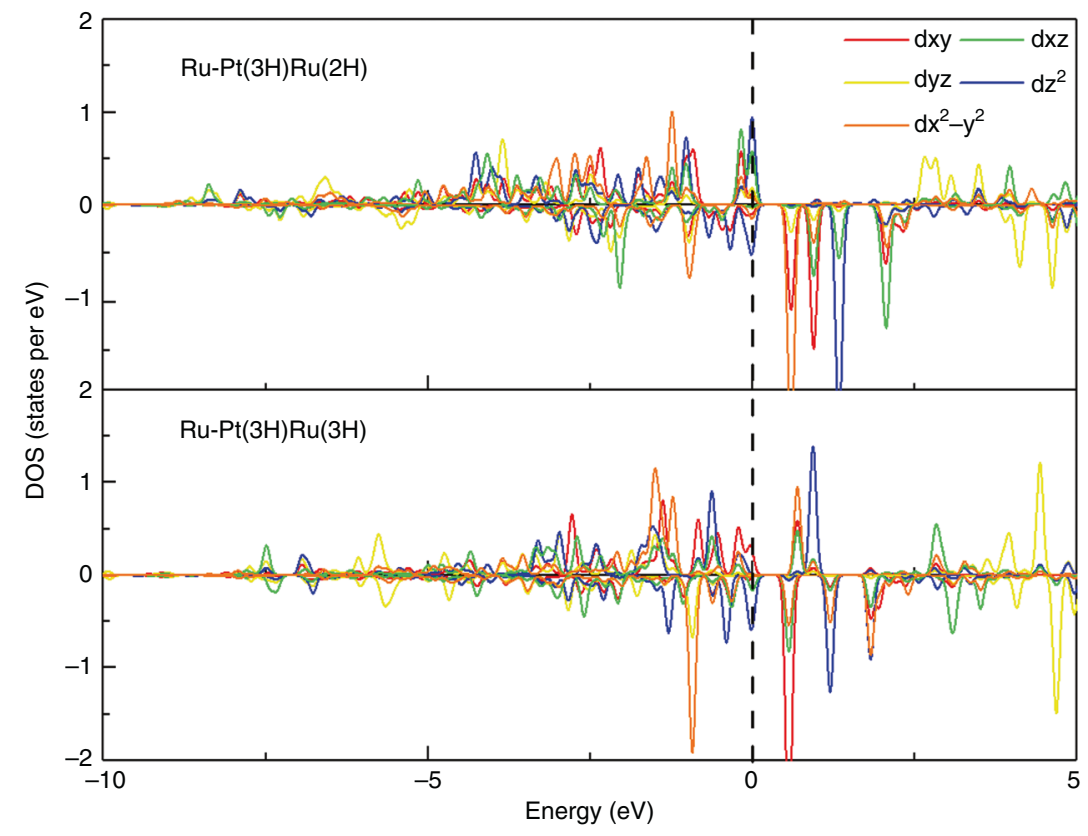

b

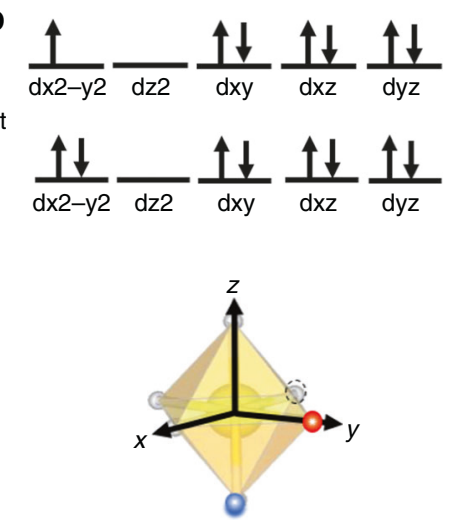

Pt in octahedron field

d

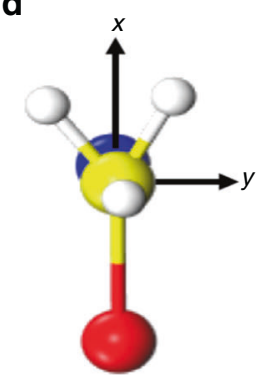

C

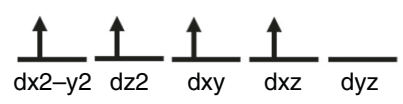

$\mathrm{Ru}$

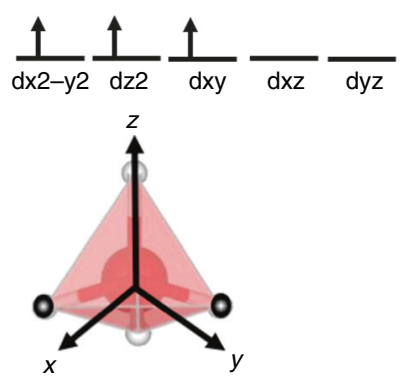

$\mathrm{Ru}$ in tetrahedron field

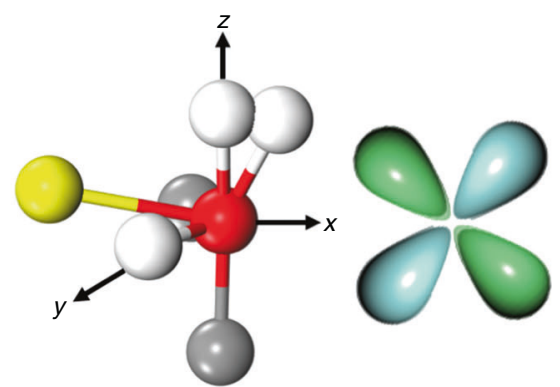

Fig. 6 Electronic structures and crystal field of the Ru atom for the last two steps. a The Projected DOS of Ru atom for $\mathrm{Pt}(3 \mathrm{H}) \mathrm{Ru}(2 \mathrm{H})$ and $\mathrm{Pt}(3 \mathrm{H}) \mathrm{Ru}(3 \mathrm{H})$. b Schematic of crystal field of Ru. c The dyz orbital of Ru of $\mathrm{Pt}(3 \mathrm{H}) \mathrm{Ru}(2 \mathrm{H})$ and the dyz orbital of $\mathrm{Ru}$ of $\mathrm{Pt}(3 \mathrm{H}) \mathrm{Ru}(3 \mathrm{H})$. Here, $\mathrm{Pt}(\mathrm{nH}) \mathrm{Ru}(\mathrm{mH}) \mathrm{represents} \mathrm{n} \mathrm{H}$ atoms adsorbed on $\mathrm{Pt}$ and $\mathrm{m} \mathrm{H}$ atoms on Ru. Red, yellow, blue and gray ball represent the $\mathrm{Ru}, \mathrm{Pt}, \mathrm{N}$ and $\mathrm{C}$ atoms, respectively

distance between the $\mathrm{Ru}$ with the $\mathrm{C}$ atoms of substructure decreases by $0.05 \AA$. The corresponding bonding between the $\mathrm{Ru}-\mathrm{C}$ is dyz, thus the antibonding state of $\mathrm{d} y z$ is pushed to a rather high energy level (see Fig. 6a). Although $\mathrm{d} x^{2}-y^{2}, \mathrm{~d} z^{2}$ and $\mathrm{d} x y$ of Ru remain half-filled, dxz changes from half-filled to fully unoccupied, and the antibonding orbital of $\mathrm{dxz}$ is greatly shifted to a rather high energy level. The hydrogen atoms on the $\mathrm{Ru}$ atom, exhibiting the smallest $\Delta G_{H}$, just interacts with the $\mathrm{dxz}$ orbital for both $\mathrm{Pt}(3 \mathrm{H}) \mathrm{Ru}(2 \mathrm{H})$ and $\mathrm{Pt}(3 \mathrm{H}) \mathrm{Ru}(3 \mathrm{H})$ (Supplementary Figs. 21 and 22 and Supplementary Table 4). Considering that $\mathrm{dxz}$ orbital of $\mathrm{Ru}$ becomes unoccupied by the synergetic effect of Pt-Ru dimer during the hydrogen adsorption, the interaction between the hydrogen and the $\mathrm{d} x z$ of $\mathrm{Ru}$ atom should be rather weak, which should be the main reason why the Pt-Ru dimer exhibits the superior HER as found in our experiment.

\section{Discussion}

To investigate the structure consistence between the catalysts and DFT models, the Feff (a software program used in XAS) 
theoretical modeling is carried out. Firstly, we investigated the consistency between the Pt single atom DFT model and EXAFS theoretical modeling. We developed 3-shell $\mathrm{R}$ space curve fitting model base on the Pt single atom DFT model. Two shells are corresponding to $\mathrm{Pt}-\mathrm{C}$ (coordination numbers, $\mathrm{CN}=2$ ) and Pt-N $(\mathrm{CN}=1)$, which construct the triangle base of the single Pt atom tetrahedron configuration. The other shell is $C$ shell $(\times 6)$, which works as connection from the single Pt atom tetrahedron configuration to the substrate. The Pt local structural environment revealed by Pt L3 edge R space curve fitting result consists what predicted by DFT in terms of single Pt atom tetrahedron configuration and its imbedded connection with the $\mathrm{N}$-doped carbon substrate Supplementary Fig. 23. As shown in Table 2, the Pt single atoms have the $\mathrm{CN}$ of 2.2 and 1.2 for Pt-C and Pt-N bonding respectively, which agrees well with our proposed DFT model.

For the dimer structure, we carried out the R space curve fitting of the $\mathrm{Pt}-\mathrm{Ru}$ dimer structure guided on the crystallography predicted DFT model. 3-single-scattering path models Pt-N (CN $=1), \mathrm{Pt}-\mathrm{Ru}(\mathrm{CN}=1)$, and $\mathrm{Pt}-\mathrm{C}(\mathrm{CN}=6)$ were used for the fitting. As shown in Supplementary Fig. 24, the overall agreement between the Feff fitting and the experimental data is revealed, suggesting that the obtained $\mathrm{Pt}-\mathrm{Ru}$ dimer catalysts supports the modeling predicted DFT model structure. In addition to R space fitting, we also used XANES linear combination fitting (LCF) to identify the existence of Pt-Ru dimers in the catalysts. Because no single phase $\mathrm{Pt}-\mathrm{Ru}$ dimer catalysts can be prepared, a corresponding experimental standard spectrum is not available for LCF analysis. The DFT guided theoretical XANES spectrum was used as a replacement in LCF. Three standard spectra, including $\mathrm{Pt}$ single atoms, Pt-Ru dimer and metallic Pt, were used for LCF analysis. As shown in Supplementary Fig. 25, LCF results a good mathematical fit. The result show that the percentage of $\mathrm{Pt}-\mathrm{Ru}$ dimer and Pt single atoms are $15 \%$ and $85 \%$, respectively. Because there are some Pt clusters in this sample, the amount of Pt single atom is overestimated. However, this data can prove the existence of certain amount Pt-Ru dimer in the sample. The above XAS fitting results (EXAFS R space curve fitting and XANES LCF analysis) strongly support the existence of $\mathrm{Pt}-\mathrm{Ru}$ dimer and the rationality of the DFT predicted model.

We also developed Ru centered spherical cluster system based on the Pt-Ru dimer DFT model (Supplementary Fig. 26a). The structural system is composed by multiple $\mathrm{Ru}$ centered clusters, starting from 2.4 $\AA, 3.0 \AA$, 4.0 $\AA$, to $5.0 \AA$. As shown in Supplementary Fig. 26b, comparison is made between experimental XANES spectrum and the best-fit of Ru XANES modeling ( $\mathrm{Ru}$ centered clusters with the radius of $5.0 \AA$ ). The spectrum of $\mathrm{Ru}$ XANES modeling with the Ru radius of $5.0 \AA$ shows a relatively strong B feature and a shoulder peak for A feature. It should be pointed that the peak intense and peak position of the fitted data might be a little different with the experimental data, because the model might have some defects compared with the actual $\mathrm{Ru}$ local structural environment of the sample. The presence of the three XANES features A, B and C can be used as the evidence of the formation of Pt-Ru dimers. Guided by the Pt-Ru dimer DFT model, an initial Feff modeling was performed based on the Ru centered cluster R5.0 $\AA$. The modeled $\mathrm{k}^{2} \chi(\mathrm{k})$ is compared to raw spectrum (Supplementary Fig. 27a), revealing a good reproducing of experimental data. The comparison was also made for the backward FT filtered $\mathrm{k}^{2} \chi(\mathrm{k})(0.9-3.3 \AA$, latched region for the 1st two FT peaks) and the modeled result (Supplementary Fig. 27b). Both comparisons reveal that the experimentally resolved $\mathrm{k}^{2} \chi(\mathrm{k})$ feature has been reproduced, supporting the reliability of the predicted Pt-Ru dimer DFT model. Based on the Pt-Ru DFT model, 5-path structure model was developed for R space curve fitting. The fitted parameters are summarized in Table 3. As

\begin{tabular}{|c|c|c|c|c|}
\hline Sample & Path & $\begin{array}{l}\text { Coordination } \\
\text { number }\end{array}$ & $\begin{array}{l}\text { Bond } \\
\text { length }(\AA)\end{array}$ & $\begin{array}{l}\sigma^{2} / 10^{-3} \\
\AA^{2}\end{array}$ \\
\hline \multirow{3}{*}{$\begin{array}{l}\text { Pt single atom } \\
\text { catalysts }\end{array}$} & Pt-N & $1.2(0.2)$ & $1.93(0.02)$ & 2.1 \\
\hline & Pt-C (1) & $2.2(0.4)$ & $2.04(0.02)$ & 1.6 \\
\hline & Pt-C (2) & $5.5(0.8)$ & $2.96(0.05)$ & 9.4 \\
\hline \multirow[t]{3}{*}{ Pt-Ru dimers } & Pt-N & $1.2(0.3)$ & $2.06(0.02)$ & 2.1 \\
\hline & $\mathrm{Pt}-\mathrm{C}$ & $5.2(0.8)$ & $2.10(0.02)$ & 8.4 \\
\hline & Pt-Ru & $1.2(0.2)$ & $2.34(0.04)$ & 6.7 \\
\hline
\end{tabular}

shown in Supplementary Fig. 28, the R space and K space curve fitting agrees well with the experimental data. From the $\mathrm{Ru} \mathrm{R}$ space fitting results, the $\mathrm{Ru}$ atoms have the $\mathrm{CN}$ of 0.7 for $\mathrm{Ru}-\mathrm{Pt}$, also suggesting the formation of $\mathrm{Pt}-\mathrm{Ru}$ dimer structure. It should be pointed out that $\mathrm{R}$ space curve fitting result (including $\mathrm{CN}$ and bond length) from Pt L3 edge and Ru K edge for the dimer Pt-Ru scattering path consists to each other. Namely, standing on Pt to see $\mathrm{Ru}$ is equivalent to standing on $\mathrm{Ru}$ to see Pt. Therefore, the spatial relation of $\mathrm{Pt}$ vs $\mathrm{Ru}$ consists the predicted dimer model by DFT.

In summary, we have successfully synthesized Pt-Ru dimers on NCNTs by the ALD method. The obtained Pt-Ru dimers showed significantly improved mass activity (more than 50 times) and excellent stability compared to commercial $\mathrm{Pt} / \mathrm{C}$ catalysts for HER. Both XAS spectra and first-principles calculations indicate that the $\mathrm{Pt}-\mathrm{Ru}$ dimers complex contains $\mathrm{Pt}-\mathrm{Ru}$ bonding. Furthermore, the first-principles calculation reveals that the $\mathrm{Pt}-\mathrm{Ru}$ dimer could be easily changed from metal to semicondutor by the adsorption, leaving unoccupied orbtials. The inertaction between $\mathrm{H}$ and $\mathrm{Ru}$ could be modulated by the Pt through the synergetic effect, which results in the high HER activity. This work provides an in-depth understanding of bimetallic dimer catalysis. Furthermore, we pave the way for the precise control of metal dimers, trimmers and even tetramers, which have great potential to be applied in various catalytic reactions.

\section{Methods}

Synthesis of NCNTs. We synthesized the NCNTs with a diameter of $100 \mathrm{~nm}$ by ultrasonic spray pyrolysis according to a previous study ${ }^{45}$. In the synthesis process, we used imidazole as carbon and nitrogen source, and ferrocene as the catalyst precursor. The reaction were carried out at $850{ }^{\circ} \mathrm{C}$. During the reaction, the ferrocene can decompose into iron particles, which acts as the catalyst for the growth of carbon nanotubes and the incorporation of nitrogen in the graphite layers to yield NCNTs. The received NCNTs were washed with nitric acid and water for $6 \mathrm{~h}$ at $80^{\circ} \mathrm{C}$, respectively. The NCNTs were loaded on aluminum foil before putting into the ALD reactor chamber.

ALD synthesis of Pt-Ru dimers on NCNTs. We used $\mathrm{MeCpPtMe}_{3}$ as the precursor for the deposition of Pt single atoms onto the NCNTs. The Pt ALD process were carried out at $250^{\circ} \mathrm{C}$ by ALD (Savannah 100, Cambridge Nanotechnology Inc., USA). The purging gas and carrier gas are both high-purity $\mathrm{N}_{2}$ (99.9995\%). The container for $\mathrm{MeCpPtMe}_{3}$ was maintained at $65^{\circ} \mathrm{C}$ for a steady-state flux of $\mathrm{Pt}$ to the chamber. Pt single atoms were obtained after a $30 \mathrm{~s}$ exposure of Pt precursor. After the formation of Pt single atoms on NCNTs, Ru atoms was selectively deposited on the Pt single atoms by using bis(ethylcyclopentadienyl)ruthenium(II) precursors. The carrier gas is high-purity $\mathrm{N}_{2}(99.9995 \%)$. The container for bis (ethylcyclopentadienyl)ruthenium(II) was heated at $110^{\circ} \mathrm{C}$ and the chamber temperature was kept at $270^{\circ} \mathrm{C}$. The gas lines were held at $150^{\circ} \mathrm{C}$. During the $\mathrm{Ru}$ ALD process, a $10 \mathrm{~s}$ exposure of Ru precursor was used for the deposition of $\mathrm{Ru}$. $\mathrm{Pt}$ and $\mathrm{Ru}$ loading were analyzed using an inductively coupled plasma-optical emission spectrometer (ICP-OES) with samples dissolved in fresh hot aqua regia and filtered.

HER activity measurements. The electrochemical HER measurements were performed using a three electrode system. The glassy carbon rotating-disk electrode (Pine Instruments) was used as the working electrode. A graphite electrode was used as the counter electrode, and a reversible hydrogen electrode (RHE) was used 
Table 3 R space fitting results from Ru K edge for Pt-Ru dimers

\begin{tabular}{|c|c|c|c|c|c|c|}
\hline Sample & Path & Coordination number & Bond length $(\AA)$ & Coordination number & Bond length $(\AA)$ & $\sigma^{2} / 10^{-3} \AA^{2}$ \\
\hline \multirow{4}{*}{ Pt-Ru dimers } & $\mathrm{Ru}-\mathrm{C}$ & 2 & 1.90 & $2.4(0.4)$ & $1.76(0.02)$ & 2.9 \\
\hline & $\mathrm{Ru}-\mathrm{C}$ & 3 & 2.58 & $2.5(0.4)$ & $2.25(0.03)$ & 7.0 \\
\hline & Ru-N & 1 & 2.87 & $1.4(0.2)$ & $2.83(0.05)$ & 2.8 \\
\hline & $\mathrm{Ru}-\mathrm{C}$ & Multiple & $\geq 3.10$ & $3.9(0.5)$ & $3.10(0.06)$ & 7.1 \\
\hline
\end{tabular}

as the reference electrode. We prepared the ink for the electrochemical measurement by mixing $3 \mathrm{mg}$ of the catalysts, $1.6 \mathrm{~mL}$ DI water, $0.4 \mathrm{~mL}$ isopropanol, and 40 $\mu \mathrm{L}$ Nafion (5\% solution, Sigma-Aldrich), followed by sonication for $10 \mathrm{~min}$. Twenty microliters of the ink was loaded onto the glassy carbon rotating dis electrode $\left(0.196 \mathrm{~cm}^{2}\right)$ for preparing the working electrode. The CVs were recorded in a $\mathrm{N}_{2}$-saturated $0.5 \mathrm{M} \mathrm{H}_{2} \mathrm{SO}_{4}$ by cycling between 0.05 and $1.1 \mathrm{~V}_{\mathrm{RHE}}$ at a scan rate of $0.05 \mathrm{~V} \mathrm{~s}^{-1}$. The HER test was carried out with a scan rate of $2 \mathrm{mV} \mathrm{s}^{-1}$. To avoid the formation of $\mathrm{H}_{2}$ gas bubbles at the catalyst surface during the HER tests, the working electrode was rotated at 1600 r.p.m.

Instrumentation. Transmission electron microscopy (TEM) samples were prepared by drop casting an ultrasonicated solution of the samples of interest dissolved in high-performance liquid chromatography grade methanol solution onto lacey carbon grids. The samples were tested on a FEI Titan Cubed $80-300 \mathrm{kV}$ microscope equipped with spherical aberration correctors (for probe and image forming lenses) at $200 \mathrm{kV}$. The STEM images were collected with a high angleannular dark field detector (HAADF) with a collection angle of 64-200 mrad.

X-ray absorption spectroscopy. We used the beamline 20-BM-B at the Advanced Photon Source (APS, Argonne National Laboratory) and the hard X-ray microanalysis (HXMA) beamline (Canadian Light Source) to obtain the Pt $\mathrm{L}_{2}, \mathrm{~L}_{3}$-edge and Ru K-edge XAS spectra. The fluorescence yield mode with a solid-state detector was used to collect each spectrum. The spectra of Pt foil and Ru metal were collected in transmission mode for comparison and monochromatic energy calibration. The Athena software was used to analyze the obtained XAS data. The extracted EXAFS data was weighted by $\mathrm{k}^{3}$, then converted to $\mathrm{R}$ space by $\mathrm{FT}$ to obtain the magnitude plots of the EXAFS spectra. The EXAFS data R space curve fitting was performed by WinXAS version $2.3^{46}$.

Quantitatively intensity analysis of XAS. The $\mathrm{Pt}_{3,2}$-edge $\mathrm{WL}$ intensity was analyzed using the Au metal $\mathrm{L}_{3,2}$-edge X-ray absorption near edge spectroscopy (XANES) as the background. The areas under the difference curve in the $\mathrm{L}_{3}$ and $\mathrm{L}_{2}$ WL region between $\mathrm{Pt}$ and $\mathrm{Au}$ were denoted as $\mathrm{A}_{3}$ and $\mathrm{A}_{2}$ at the respectively. The area under the difference curve was integrated between the two vertical bars. The $\Delta \mathrm{A}_{3}$ and $\Delta \mathrm{A}_{2}$ were obtained according to the following equations:

$$
\begin{gathered}
\Delta A_{3}=\int(\mathrm{Pt})_{\mathrm{L} 3 W \mathrm{~L}}-\mu(\mathrm{Au})_{\mathrm{L} 3 \mathrm{WL}} \\
\Delta A_{2}=\int(\mathrm{Pt})_{\mathrm{L} 2 \mathrm{WL}-\mu(\mathrm{Au})_{\mathrm{L} 2 \mathrm{WL}}}
\end{gathered}
$$

and according to Sham et al. ${ }^{38}$, the $\Delta A_{3}$ and $\Delta A_{2}$ values were able to be calculated from the following equations:

$$
\begin{aligned}
& \Delta A_{3}=C_{0} N_{0} E_{3}\left(R_{d}^{2 p^{2} / 3}\right)^{2}\left[\frac{6 h_{\frac{5}{2}}+h_{\frac{3}{2}}}{15}\right] \\
& \Delta A_{2}=C_{0} N_{0} E_{2}\left(R_{d}^{2 p^{1} / 2}\right)^{2}\left(\frac{1}{3} h^{3 / 2}\right)
\end{aligned}
$$

where $C_{0}=4 \pi \gamma^{2} \alpha / 3$ ( $\alpha$ is the fine structure constant), $N_{0}$ is the density of Pt atoms, and $E_{2}$ and $E_{3}$ are the $E_{0}$ for the $\mathrm{L}_{2}$ and $\mathrm{L}_{3}$ edges, respectively. The $R$ is the radial transition matrix element, and $h_{j}$ is the $5 \mathrm{~d}$ hole counts. By assuming $R$ terms are similar for both edges

$$
C=C_{0} N_{0} R^{2}
$$

$C$ value of $7.484 \times 10^{4} \mathrm{~cm}^{-1}$ was derived previously for Pt metal. and with this approximation

$$
\begin{gathered}
h_{3 / 2}=\left[\frac{3 \Delta A_{2}}{C}\right] \\
h_{5 / 2}=\frac{1}{2 C}\left[5 \frac{E_{2}}{E_{3}} \Delta A_{3}-\Delta A_{2}\right]
\end{gathered}
$$

The calculated d hole counts $\left(h_{5 / 2}\right.$ and $\left.h_{3 / 2}\right)$ are listed in Table 1 .
Computational method. We performed first-principles calculations by the $\mathrm{CP} 2 \mathrm{~K} /$ Quickstep package ${ }^{47}$. The correlation energies and nonlocal exchange were described by Perdew-Burke-Ernzerhof functional ${ }^{48}$. The norm-conserving GTH pseudopotentials were used to describe the core electrons ${ }^{49}$. The m-DZVP were used for expanding the wave function of $N 1 s^{2} 2 s^{2} 2 p^{3}$ and $C 1 s^{2} 2 s^{2} 2 p^{2}$, and $m-$ TZVP for Ru $4 s^{2} 4 \mathrm{p}^{6} 4 \mathrm{~d}^{7} 5 \mathrm{~s}^{1}$ and Pt $4 \mathrm{~s}^{2} 4 \mathrm{p}^{6} 5 \mathrm{~d}^{9} 6 \mathrm{~s}^{1}$ electrons $\mathrm{s}^{50}$. The cut off energy of auxiliary basis set of plane waves is $500 \mathrm{Ry}$. During the calculations, all the atomic positions were fully relaxed until the force is smaller than $0.05 \mathrm{eV} / \mathrm{A}$. We performed FPMD by CP2K/Quickstep package.

The hydrogen adsorption energies, $E_{\text {ad }}$, were calculated according to the following equations,

$$
E \mathrm{ad}=1 / n\left(E_{n \mathrm{H} / \text { metallic dimer }}-E_{\text {metallic dimer }}-n / 2 E \mathrm{H}_{2}\right)
$$

$E_{n \mathrm{H} / \text { metallic dimer }}$ and $E_{\text {metallic dimer }}$ represent the total energies of $n$ hydrogen atoms adsorbed on metallic dimer and metallic dimer, respectively. $E_{\mathrm{H} 2}$ is the total energy of one hydrogen molecule in vacuum, $n$ refers to the number of hydrogen atoms adsorbed on metallic dimer.

The hydrogen-adsorption Gibbs free energies, $\Delta G_{\mathrm{H}}$, were calculated according to the following equations ${ }^{44}$,

$$
\begin{gathered}
\Delta E_{\mathrm{H}}=E_{(\mathrm{n}+1) \mathrm{H} / \text { metal }}-E_{\mathrm{nH} / \text { metal }}-1 / 2 E_{\mathrm{H} 2} \\
\Delta G_{\mathrm{H}}=\Delta E_{\mathrm{H}}+\Delta E_{\mathrm{ZPE}}-T \Delta S
\end{gathered}
$$

We defined the $\Delta E_{\mathrm{H}}$ as the hydrogen binding energy on metal atoms. $E_{(n+1) \mathrm{H} /}$ metal and $E_{n \mathrm{H} / \text { metal }}$ represent the total energies of $n+1$ and $n$ hydrogen atoms adsorption on metal atom, respectively. $E_{\mathrm{H} 2}$ represent the total energy of one hydrogen molecule in vacuum. $\Delta E_{\mathrm{ZPE}}$ is the difference of the zero-point energy with and without hydrogen adsorption, $T$ is $300 \mathrm{~K}$, and $\Delta S$ is the entropy change between an adsorbed hydrogen and gas-phase hydrogen at 101,325 $\mathrm{Pa}$.

\section{Data availability}

All data are available from the authors, please refer to author contributions for specific data sets. Source data are provided as a Source Data file.

Received: 6 May 2019; Accepted: 25 September 2019; Published online: 30 October 2019

\section{References}

1. Debe, M. K. Electrocatalyst approaches and challenges for automotive fuel cells. Nature 486, 43-51 (2012).

2. Zhang, H., Liu, G., Shi, L. \& Ye, J. Single-atom catalysts: emerging multifunctional materials in heterogeneous catalysis. Adv. Energy Mater. 8, 1701343 (2018).

3. Tian, N. et al. Rational design and synthesis of low-temperature fuel cell electrocatalysts. Electrochem. Energ. Rev. 1, 54-83 (2018).

4. Zhang, L., Doyle-Davis, K. \& Sun, X. Pt-Based electrocatalysts with high atom utilization efficiency: from nanostructures to single atoms. Energy Environ. Sci. 12, 492-517 (2019).

5. Wang, A., Li, J. \& Zhang, T. Heterogeneous single-atom catalysis. Nat. Rev. Chem. 2, 65-81 (2018).

6. Yang, X.-F. et al. Single-atom catalysts: a new frontier in heterogeneous catalysis. Acc. Chem. Res. 46, 1740-1748 (2013).

7. Liu, J. Catalysis by supported single metal atoms. ACS Catal. 7, 34-59 (2017).

8. Zhu, C. et al. Single-atom electrocatalysts. Angew. Chem. Int. Ed. 56, 13944-13960 (2017).

9. Qiao, B. et al. Single-atom catalysis of $\mathrm{CO}$ oxidation using $\mathrm{Pt}_{1} / \mathrm{FeO}_{\mathrm{x}}$. Nat. Chem. 3, 634-641 (2011).

10. Lin, J. et al. Remarkable performance of $\mathrm{Ir}_{1} / \mathrm{FeO}_{\mathrm{x}}$ single-atom catalyst in water gas shift reaction. J. Am. Chem. Soc. 135, 15314-15317 (2013). 
11. Lin, J. et al. Design of a highly active $\mathrm{Ir} / \mathrm{Fe}(\mathrm{OH})_{\mathrm{x}}$ catalyst: versatile application of Pt-group metals for the preferential oxidation of carbon monoxide. Angew. Chem. Int. Ed. 51, 2920-2924 (2012).

12. Lin, J. et al. Little do more: a highly effective $\mathrm{Pt}_{1} / \mathrm{FeO}_{\mathrm{x}}$ single-atom catalyst for the reduction of $\mathrm{NO}$ by $\mathrm{H}_{2}$. Chem. Comm. 51, 7911-7914 (2015).

13. Lin, L. et al. Low-temperature hydrogen production from water and methanol using Pt/ $\alpha$-MoC catalysts. Nature 544, 80-83 (2017).

14. Yang, S. et al. Single-atom catalyst of platinum supported on titanium nitride for selective electrochemical reactions. Angew. Chem. Int. Ed. 55, 2058-2062 (2016).

15. Liu, J. et al. High performance platinum single atom electrocatalyst for oxygen reduction reaction. Nat. Commun. 8, 15938 (2017).

16. Zhang, J. et al. Cation vacancy stabilization of single-atomic-site $\mathrm{Pt}_{1} / \mathrm{Ni}(\mathrm{OH})_{\mathrm{x}}$ catalyst for diboration of alkynes and alkenes. Nat. Commun. 9, 1002 (2018).

17. Sun, S. et al. Single-atom catalysis using Pt/graphene achieved through atomic layer deposition. Sci. Rep. 3, 1775 (2013).

18. Cheng, N. et al. Platinum single-atom and cluster catalysis of the hydrogen evolution reaction. Nat. Commun. 7, 13638 (2016).

19. Cao, Y. et al. Atomic-level insight into optimizing the hydrogen evolution pathway over a $\mathrm{Co}_{1}-\mathrm{N}_{4}$ single-site photocatalyst. Angew. Chem. Int. Ed. 56 12191-12196 (2017).

20. Yan, H. et al. Bottom-up precise synthesis of stable platinum dimers on graphene. Nat. Commun. 8, 1070 (2017).

21. Yan, $\mathrm{H}$. et al. Single-atom $\mathrm{Pd}_{1}$ /graphene catalyst achieved by atomic layer deposition: remarkable performance in selective hydrogenation of 1,3butadiene. J. Am. Chem. Soc. 137, 10484-10487 (2015).

22. Kistler, J. D. et al. A single-site platinum CO oxidation catalyst in zeolite KLTL: Microscopic and spectroscopic determination of the locations of the platinum atoms. Angew. Chem. Int. Ed. 53, 8904-8907 (2014).

23. Liu, L. et al. Generation of subnanometric platinum with high stability during transformation of a 2D zeolite into 3D. Nat. Mater. 16, 132-138 (2016).

24. Wei, S. et al. Direct observation of noble metal nanoparticles transforming to thermally stable single atoms. Nat. Nanotechnol. 13, 856-861 (2018).

25. Chen, Y. et al. Discovering partially charged single-atom Pt for enhanced antimarkovnikov alkene hydrosilylation. J. Am. Chem. Soc. 140, 7407-7410 (2018).

26. Chen, Y. et al. Single-atom catalysts: synthetic strategies and electrochemical applications. Joule 2, 1242-1264 (2018).

27. He, Y. et al. Metal-nitrogen-carbon catalysts for oxygen reduction in PEM fuel cells: self-template synthesis approach to enhancing catalytic activity and stability. Electrochem. Energ. Rev. https://doi.org/10.1007/s41918-019-00031-9 (2019).

28. Yang, H. B. et al. Atomically dispersed $\mathrm{Ni}(\mathrm{I})$ as the active site for electrochemical $\mathrm{CO}_{2}$ reduction. Nat. Energy 3, 140-147 (2018).

29. Liu, P. et al. Photochemical route for synthesizing atomically dispersed palladium catalysts. Science 352, 797-800 (2016).

30. Li, T., Liu, J., Song, Y. \& Wang, F. Photochemical solid-phase synthesis of platinum single atoms on nitrogen-doped carbon with high loading as bifunctional catalysts for hydrogen evolution and oxygen reduction reactions. ACS Catal. 8, 8450-8458 (2018).

31. Wei, H. et al. Iced photochemical reduction to synthesize atomically dispersed metals by suppressing nanocrystal growth. Nat. Commun. 8, 1490 (2017).

32. Wang, J. et al. Design of N-coordinated dual-metal sites: a stable and active Pt free catalyst for acidic oxygen reduction reaction. J. Am. Chem. Soc. 139, 17281-17284 (2017)

33. Lu, Z. et al. An isolated zinc-cobalt atomic pair for highly active and durable oxygen reduction. Angew. Chem. Int. Ed. 58, 2622-2626 (2019).

34. Diao, W., Tengco, J. M. M., Regalbuto, J. R. \& Monnier, J. R. Preparation and characterization of $\mathrm{Pt}-\mathrm{Ru}$ bimetallic catalysts synthesized by electroless deposition methods. ACS Catal. 5, 5123-5134 (2015).

35. Tess, M. E. et al. Bimetallic Pt/Ru complexes as catalysts for the electrooxidation of methanol. Inorg. Chem. 39, 3942-3944 (2000)

36. Zhang, L. et al. Selective atomic layer deposition of RuOx catalysts on shapecontrolled Pd nanocrystals with significantly enhanced hydrogen evolution activity. J. Mater. Chem. A 6, 24397-24406 (2018).

37. Wang, D. et al. Electronic behaviour of Au-Pt alloys and the $4 \mathrm{f}$ binding energy shift anomaly in Au bimetallics- X-ray spectroscopy studies. AIP Adv. 8, 065210 (2018).

38. Sham, T., Naftel, S. \& Coulthard, I. $\mathrm{M}_{3,2}$-edge X-ray absorption near-edge structure spectroscopy: An alternative probe to the $\mathrm{L}_{3,2}$-edge near-edge structure for the unoccupied densities of d states of 5d metals. J. Appl. Phys. 79, 7134-7138 (1996).

39. $\mathrm{Hu}, \mathrm{P}$. et al. Electronic metal-support interactions in single-atom catalysts. Angew. Chem. Int. Ed. 53, 3418-3421 (2014).

40. Qu, Y. et al. Thermal emitting strategy to synthesize atomically dispersed Pt metal sites from bulk Pt metal. J. Am. Chem. Soc. 14, 4505-4509 (2019).

41. Wang, X. et al. Uncoordinated amine groups of metal-organic frameworks to anchor single $\mathrm{Ru}$ sites as chemoselective catalysts toward the hydrogenation of quinolone. J. Am. Chem. Soc. 139, 9419-9422 (2017).

42. Xue, Y. et al. Anchoring zero valence single atoms of nickel and iron on graphdiyne for hydrogen evolution. Nat. Commun. 9, 1460 (2018).
43. Wang, X. et al. Regulation of coordination number over single Co sites: Triggering the efficient electroreduction of $\mathrm{CO}_{2}$. Angew. Chem. Int. Ed. 57, 1944-1948 (2018)

44. Skúlason, E. et al. Modeling the electrochemical hydrogen oxidation and evolution reactions on the basis of density functional theory calculations. $J$. Phys. Chem. C 114, 18182-18197 (2010).

45. Bulusheva, L. G. et al. Synthesis of carbon nanotubes with catalytic ironcontaining proteins. Carbon 49, 4013-4023 (2011).

46. Ressler, T. WinXAS: A new software package not only for the analysis of energy-dispersive XAS Data. J. Phys. IV 7, 269-270 (1997).

47. VandeVondele, J. et al. Quickstep: Fast and accurate density functional calculations using a mixed Gaussian and plane waves approach. Comput. Phys. Commun. 167, 103-128 (2005).

48. Tao, J., Perdew, J. P., Staroverov, V. N. \& Scuseria, G. E. Climbing the density functional ladder: Nonempirical meta-generalized gradient approximation designed for molecules and solids. Phys. Rev. Lett. 91, 146401 (2003).

49. Hartwigsen, C., Goedecker, S. \& Hutter, J. Relativistic separable dual-space Gaussian pseudopotentials from H to Rn. Phys. Rev. B 58, 3641-3662 (1998).

50. VandeVondele, J. \& Hutter, J. Gaussian basis sets for accurate calculations on molecular systems in gas and condensed phases. J. Chem. Phys. 127, 114105 (2007).

\section{Acknowledgements}

This work was supported by Natural Sciences and Engineering Research Council of Canada (NSERC), Canada Research Chair (CRC) Program, Canada Foundation for Innovation (CFI) and the University of Western Ontario. The electron microscopy characterization was carried out at the Canadian Centre for Electron Microscopy (CCEM), a national facility supported by NSERC, the Canada Foundation for Innovation (via the MSI program) and McMaster University. LLM was supported by the Science Challenge Project (TZ2018004), the Fundamental Research Funds for the Central Universities, the National Natural Science Foundation of China (grant no. 51861130360 , 51572016, and U1530401), and Newton Advanced Fellowships under the grant No. $\mathrm{NAF} / \mathrm{R} 1 / 180242$, the computation supports from Tianhe-2JK computing time award at the Beijing Computational Science Research Center (CSRC).

\section{Author contributions}

L.Z. conceived and designed the experimental work and prepared the manuscript; H.L. Q.W., M.G. and G.B. carried out atomic-resolution STEM tests; R.S. and L.L. performed the DFT calculations; M.N.B., Z.S., J.L. and R.L. helped with ALD characterization and ICP-OES test; N.C., K.A., Z.W., J.C., and T.S. carried out the X-ray absorption fine structure and analysis; X.S. supervised the overall project. All authors have given approval to the final version of the manuscript.

\section{Competing interests}

The authors declare no competing interests.

\section{Additional information}

Supplementary information is available for this paper at https://doi.org/10.1038/s41467 019-12887-y.

Correspondence and requests for materials should be addressed to L.-M.L., G.A.B. or X.S.

Peer review information Nature Communications thanks the anonymous reviewers for their contributions to the peer review of this work. Peer review reports are available.

Reprints and permission information is available at http://www.nature.com/reprints

Publisher's note Springer Nature remains neutral with regard to jurisdictional claims in published maps and institutional affiliations.

\section{(i)}

Open Access This article is licensed under a Creative Commons Attribution 4.0 International License, which permits use, sharing, adaptation, distribution and reproduction in any medium or format, as long as you give appropriate credit to the original author(s) and the source, provide a link to the Creative Commons license, and indicate if changes were made. The images or other third party material in this article are included in the article's Creative Commons license, unless indicated otherwise in a credit line to the material. If material is not included in the article's Creative Commons license and your intended use is not permitted by statutory regulation or exceeds the permitted use, you will need to obtain permission directly from the copyright holder. To view a copy of this license, visit http://creativecommons.org/ licenses/by/4.0/.

(C) The Author(s) 2019 